\title{
EL CUIDADO COMO ESTRATEGIA DE SUPERVIVENCIA HUMANA Discapacidad, género y salud
}

CUIDADOS COMO ESTRATÉGIA DE SOBREVIVÊNCIA HUMANA:

Deficiência, gênero e saúde

DANIELA VERÓNICA MAZA ${ }^{1}$

\section{RESUMEN}

En el presente trabajo se analizará la trascendencia del cuidado para la sostenibilidad de la vida de las personas, en particular de las personas con discapacidad en situación de dependencia. Se indagará en las características que presenta el cuidado, las respuestas jurisdiccionales, y las normas y criterios establecidos para brindar a las familias los apoyos para garantizar la sostenibilidad del dispositivo de cuidado.

PALABRAS CLAVE: Cuidado. Personas con discapacidad. Apoyos. Familismo.

\section{RESUMO}

Neste trabalho, será analisada a importância do cuidado com a sustentabilidade da vida das pessoas, em particular para as pessoas com deficiência em situações de dependência. Serão investigadas as características do atendimento, respostas jurisdicionais e as normas e critérios estabelecidos para fornecer às famílias os apoios para garantir a sustentabilidade do dispositivo de atendimento.

PALAVRAS-CHAVE: Assistência. Pessoas com deficiência. Apoio. Familismo.

1 Doctoranda en Ciencias Jurídicas. Universidad del Museo Social Argentino. Especializada en Género y Derecho. Universidad de Buenos Aires. Diplomada en Gestión de Organizaciones con Perspectiva de Género. Universidad Abierta Interamericana. Especialista en Políticas Públicas y Justicia de Género. Consejo Latinoamericano de Ciencias Sociales. Especialista en Derecho Penal. Universidad de Salamanca. Técnica en igualdad de Género. EUROINNOVA. Maestranda en Estudios de Género. Universidad de Ciencias Empresariales y Sociales. Profesora en la Especialización de Psicología Forense de la UBA, docente invitada especialista en la Cátedra de Instituciones de Derecho Público de la Facultad de Derecho de la Universidad de Lomas de Zamora, Facultad de Ciencias Económicas de la UBA y de Psicología de la UBA. Expositora en Congresos Nacionales e Internacionales; recibió el "Premio Formación Judicial 2018" (2 puesto) otorgado por la Escuela Judicial del Poder Judicial de la Ciudad de Buenos Aires, convocado por La temática "Innovaciones en Gestión Judicial", cuyo trabajo fue titulado "Gender Compliance, un sistema de cumplimiento de estándares de género"; y "Mención Honorífica" Concurso "Premio Reflejar 2018" sobre "Las nuevas tecnologías en el servicio de justicia" con el trabajo titulado "CIBER ACCESO A JUSTICIA". Delegada por la Ciudad de Buenos Aires de la Asociación de Mujeres Juezas de Argentina. Defensora Pública coadyuvante de la Defensoría ante los Tribunales Federales de la Ciudad Autónoma de Buenos Aires. dvmaza@yahoo.com.ar 


\section{EL CUIDADO Y SUPERVIVENCIA}

El éxito reproductivo de las especies depende de los mecanismos que adopten para garantizar la supervivencia y la reproducción de su descendencia y así, asegurar la continuidad a lo largo del tiempo, manifestaba en una interesante entrevista la Dra. Sartor, investigadora Doctorada en biología con orientación en ecología de la Universidad Nacional de Córdoba. Explicaba que las especies animales utilizan diferentes estrategias comportamentales para garantizar su permanencia en el tiempo, siendo el cuidado parental una de ellas, el cual plantea decisiones como por ejemplo el número de crías, la inversión de energía en una determinada cría a costa de las reservas del presupuesto parental para otras crías. Pero es el ambiente (el filtro ambiental, según Darwin) el que determina qué estrategia comportamental será la adecuada. Si el ambiente se modifica, estrategias que eran exitosas ahora pueden no serlo, por ejemplo: la elección de la estrategia de los anfibios, aves, mamíferos, etc. estará determinada por el riesgo que enfrentan sus crías cuando nacen o en función de la autosuficiencia, el entorno y el lugar. En cuanto a los seres humanos, la biología entiende que el factor social es determinante de su comportamiento y mecanismos de supervivencia.

Estas nociones provenientes de la biología permiten considerar que la incorporación masiva en el mercado laboral y la presencia de otros factores determinantes como la disminución de la tasa de mortalidad infantil y prolongación de la esperanza de vida, deberían haber modificado las estrategias de cuidado para favorecer el recambio y supervivencia de la población a lo largo del tiempo como especie específicamente en relación con el cuidado parental, asumido históricamente por las mujeres (por ej. En la distribución, incorporación de otros actores en el cuidado, el fortalecimiento de las redes de apoyo para encararlo, en la cuantificación y valoración del trabajo de cuidado, etc.), ya que de no hacerlo, la especie humana estaría poniéndose en riesgo y comprometiendo su sostenibilidad.

\section{EL CUIDADO DESDE UN ENFOQUE DE DERECHOS}

Abordar el cuidado desde el punto de vista jurídico representa un gran desafío, ya que ha tenido una importante recepción en el ámbito de las ciencias sociales, adquiriendo mayor complejidad en la última década. La gran evolución literaria en el ámbito de la antropología, sociología, historia, economía, filosofía, e inclusive por disciplinas como la medicina, demostró que es un campo que debe ser explorado desde otros saberes, brindando la ciencia jurídica significativos aportes relativos al enfoque de derechos que hoy parece imponerse frente a las dificultades que se presentan para satisfacer las demandas de quienes por su discapacidad se encuentran en situación de dependencia, siendo una línea de abordaje central para avanzar en su determinación.

La noción de cuidado en las políticas de protección social y bienestar social se ha vuelto clave para el análisis y la investigación con perspectiva de género, y por su riqueza y densidad teórica, el cuidado es, tanto en la academia como en la política, un concepto potente 
y estratégico, capaz de articular debates y agendas antes dispersas, de generar consensos básicos y de avanzar en una agenda de equidad de género en la región².

Las regulaciones destinadas a garantizar el bienestar físico y emocional cotidiano de las personas con algún nivel de dependencia se denominan políticas de cuidado y son muy recientes en la agenda del Estado. Ellas intervienen en la forma en la que la sociedad organiza el cuidado y establecen los derechos al cuidado ${ }^{3}$. Estas políticas consideran tanto a los destinatarios del cuidado, como a las personas proveedoras e incluyen medidas destinadas tanto a garantizar el acceso a servicios, tiempo y recursos para cuidar y ser cuidado, como a velar por su calidad mediante regulaciones y supervisiones ${ }^{4}$.

En América Latina el Consenso de Quito (2007) aprobado por los gobiernos de la región marco un hito en el empoderamiento del cuidado como problema a ser abordado por los Estados, no sólo en términos de compromisos asumidos sino también de difusión de diagnósticos. Posteriormente, el Consenso de Brasilia (2010) refrena y amplía estos compromisos, haciendo referencia explícita al derecho al cuidado y a la obligación de establecer servicios de cuidado, así como licencias parentales y otras regulaciones afines. En esta dirección una alerta importante es que, si bien la agenda del cuidado en nuestra región ha sido impulsada por la agenda de género, a medida que avanza se puede ir vislumbrando en muchos de los países que el vínculo se desprende, haciéndose cada vez más énfasis en la satisfacción de las necesidades de los receptores dependientes, como lo es en Uruguay. Pese a ello, aún la traducción del cuidado en políticas y su implementación ha sido relativamente escasa y lenta en la región. Sus riesgos asociados permanecen anclados en las familias, y se ha tendido a desconocer la relevancia del cuidado como parte sustancial de los sistemas de protección social. De allí que la División de Desarrollo Social, mediante el desarrollo de investigación y de asesoría técnica, busca posicionar al cuidado como un pilar de la protección social y las políticas públicas. Se postula que la perspectiva de derechos debe abarcar tanto la condición de los sujetos de cuidado como de las personas cuidadoras; por otra parte, el derecho a cuidar, a ser cuidado y autocuidarse es indispensable para ejercer otros derechos humanos. En el caso de la infancia temprana, debe buscarse dar un salto en el desarrollo de las destrezas y capacidades infantiles mediante intervenciones tempranas que son críticas para el desarrollo cognitivo, y que pueden disminuir las desigualdades sociales. En el caso de las personas adultas mayores vulnerables y dependientes y de las personas con discapacidad, el cuidado debe promover su actividad y autonomía y actuar contra su aislamiento social. En el caso de las personas cuidadoras, la organización social del cuidado vela por ampliar sus opciones vitales. $^{5}$

2 Salvador, S.. Políticas de Cuidado en el Salvador. Asuntos de género ,CEPAL. 2015. 10-13.

3 Observatorio de Igualdad de Género de América Latina y el Caribe. División de Asuntos de Género. ONU. CEPAL. Consultado el 14/9/2019. Disponible en: https://oig.cepal.org/es/leyes/leyes-de-cuidado?page=3

4 Artículo - copia fiel del publicado en la revista Nueva Sociedad No 256, marzo-abril de 2015, ISSN: 0251-3552.

5 Página Oficial CEPAL. Consultado el 12/01/2019. Organización de Naciones Unidas. Disponible en: https://www.cepal.org/ es/sobre-el-cuidado-y-las-politicas-de-cuidado 


\section{EL ORIGEN DE LA TRANSFORMACIÓN}

Acostumbramos a considerar el cuidado como una relación binaria en la cual estaban involucradas la persona receptora y la dadora de los cuidados, quedando emplazada dicha relación en el ámbito de la familiar; no obstante, la literatura del cuidado señala que es un vínculo que responde a relaciones de género, familiares, comunitarias, políticas públicas, intervenciones de expertos y profesionales, redes migratorias y relaciones económicas. A pesar de que la modernidad enlazó en su discurso hegemónico la importancia de la autonomía, el voluntarismo y el egoísmo como eje central para el desarrollo y el crecimiento de las naciones, son las relaciones humanas de interdependencia las que nos constituyen como sujetos y las que dan identidad a nuestras sociedades. Del mismo modo, que cuando las personas llegan a edad adulta se invisibiliza la interdependencia, y el paradigma del individualismo autosuficiente suele borrar las relaciones sociales que sostienen la vida de quienes salen al mercado, convirtiendo a las personas que llevan a cabo el trabajo doméstico y de cuidados en hilos invisibles, pues nunca se muestran los hilos con los que se teje esa capacidad social. ${ }^{6}$

Para la administración de justicia es clave comprender que las actividades de cuidado se encuentran atravesadas por un proceso de menosprecio y desvalorización social, y dato sustancial para otorgar respuestas jurisdiccionales que contemplen el complejo entramado que históricamente ha dejado de lado el trabajo de cuidado realizado por las mujeres o, según lo señala Brovelli, por personas que se encuentran en una situación de vulnerabilidad psico/ social dentro de la familia ${ }^{7}$ puesto que, de no hacerlo, se corre el riesgo de afectar los derechos de personas que hoy gozan de una especial protección jurídica ${ }^{8}$.

Las transformaciones sociales ocurridas en los últimos tiempos, han modificado significativamente la demanda de cuidado, especialmente con relación a las personas con discapacidad (en adelante PCD). Conforme las exigencias derivadas del actual ordenamiento jurídico, ello impone la urgente revisión de las políticas públicas estructurales existentes y el diseño de otras nuevas dirigidas a fortalecer la transversalización de la perspectiva de género y de cuidados en los órganos vitales del Estado. Nos encontramos frente a una gran oportunidad para vigorizar su institucionalidad y proporcionar respuestas adecuadas a los problemas sociales y económicos, mediante la creación de áreas especializadas, la búsqueda de diseños más eficaces y eficientes, con la visión interseccional, que permitan elaborar diagnósticos precisos, monitorear, evaluar y mejorar continuadamente las políticas públicas de cuidado.

6 Ramaciotti, Karina; Zangaro, Marcela. "Los derroteros del cuidado". Universidad de Quilmes. ISBN 978-987-558-550-8. 1ra. Edición. Provincia de Buenos Aires. 2019:9.

7 Brovelli, Karina. Cuando el cuidado no es un asunto de mujeres. Organización de los cuidados por parte de personas en situación de vulnerabilidad psico/social. Revista Argentina de Terapia Ocupacional. Año 1. Nro. 1. Diciembre de 2015. ISSN. 2469-1143. Esta investigadora que exploró en los perfiles de las personas que se ocupan del cuidado en el ámbito familiar. La investigadora examinó las prácticas de cuidado al interior de los grupos familiares en los que el papel de cuidador/a es desempeñado por aquel miembro de la familia que se encuentra en situación de vulnerabilidad psicosocial, observó una feminización de estas personas, pero concluye que es su posición vulnerable/subordinada al interior del grupo familiar que las hace depositarias de las responsabilidades de cuidado ya sean varones o mujeres. Además señala que observó una doble invisibilización de estas personas ya que se suma a este rol la situación de vulnerabilidad psicosocial, que históricamente implicó desconocimiento de derechos.

8 Convención para la Eliminación de Todas Formas de Discriminación Contra la Mujer, Convención Interamericana para Prevenir, Sancionar y Erradicar la Violencia contra la Mujer "Belem do Pará", el cual establece un mecanismo de seguimiento de la convención (MESECVI) para evaluar y apoyar continua e independientemente a los Estados firmantes, Art. 75 inc. 22 y 23 de la Constitución Nacional. Ley 26.485. 
El cuidado de la salud de las PCD en situación de dependencia y sus familias, ha sido garantizado y protegido mediante la jerarquización Constitucional de Tratados Internacionales $^{9}$, luego operativizados por leyes y reglamentaciones. Asimismo, se observa que el cambio de paradigma sobre la discapacidad adoptado en la Convención Sobre los Derechos de las Personas con Discapacidad, propició el nacimiento de nuevas obligaciones, visibilizó otros actores responsables, cuestionó nuevas formas de pensar el cuidado terapéutico y asistencial, y obligó a quien interviene en su organización, especialmente al Poder Ejecutivo, pero también a los Poderes Legislativo y Judicial, a reflexionar sobre las transformaciones urgentes y necesarias e iniciar una etapa, aún vigente, de adecuación jurídico/normativa y de promoción y remoción de patrones estereotipados respecto de las PCD y de quienes deben proveer cuidados.

Entre las transformaciones aludidas, encontramos la modificación de la Ley Nro. 24.901 (2009), introducida por Ley 26. 480, que incorpora la asistencia domiciliaria como un novedoso dispositivo dentro del sistema de prestaciones básicas para brindar los apoyos necesarios para que las PCD recuperen o conserven las funciones de autovalidamiento para la vida diaria, facilitando la articulación y sostenibilidad del cuidado, quedando instituido un nuevo apoyo para su familia, evitando de esta forma la institucionalización de las personas con déficit de autonomía y/o deficiencias crónicas.

Este mecanismo permite que las familias articulen su dinámica organizacional, liberando tiempo para la realización de otras actividades (laborales, terapéuticas, educativas, sociales y de esparcimiento), aliviando la intensidad de los cuidados, optimizando los tiempos de relación, facilitando el mantenimiento de vínculos afectivos sanos, la sostenibilidad del cuidado y el autocuidado de las PCD y sus cuidadoras. Otro efecto importante de destacar es de carácter patrimonial, puesto que la distribución del costo del cuidado colabora con la preservación del nivel de gastos en la familia, evita el agobio financiero y valora este trabajo como elemento esencial para el desarrollo de la vida. A su vez, la desfamiliarización de la gestión administrativa para obtener la cobertura contribuye a proveer mayor cantidad de tiempo para que demás integrantes de las familias puedan realizar otras actividades para su desarrollo personal y/o profesional. En definitiva, se obtiene un impacto generizado disuasivo que impide la perpetuación de estereotipos de género en relación con el cuidado personal.

Si se indaga en los estándares jurídicos para la protección y cuidados de las PCD en situación de dependencia y sus cuidadoras, encontramos que la Convención sobre los Derechos de las Personas con Discapacidad reconoce expresamente que las familias tienen el derecho a recibir apoyos en su Preámbulo al señalar que: “...x) la familia es la unidad colectiva natural y fundamental de la sociedad y tiene derecho a recibir protección de ésta y del Estado, y de que las personas con discapacidad y sus familiares deben recibir la protección y la asisten-

9 [Cfr. Art. 42 y 75 inc. 22 de la CN; Declaración Americana de los Derechos y Deberes del Hombre (1, 5, 6, 7, 11, 12, 15, 16, 17, 18, 23, 24 y 35); Declaración Universal de los Derechos Humanos (art. 10, 25 y 26); Convención Americana Sobre los Derechos Humanos o Pacto San José de Costa Rica (art. 1, 2, 5, 7, 8, 17, 19, 24, 25, 26 y 29); Pacto Internacional de Derechos Económicos, Sociales y Culturales (art. 3, 5, 6, 7, 9, 10, 12, 13 y 15); Pacto Internacional de Derechos Civiles y Políticos y su Protocolo Facultativo (art. 1, 3, 6, 7, 8, 9, 17, 23, 24 y 26); Convención para la Eliminación de Todas Formas de Discriminación Contra la Mujer (art. 2, 3, 4, 5, 6, 10, 11, 12, 13, 14 y 16); Convención de los derechos del Niño (art. 2, 3, 4, 5, 6, 9,12, 16, 18, 19, 23, 24, 25, 26, 27 y 39); Convención Sobre los Derechos de las Personas con Discapacidad (art. 4, 5, 6, 7, 25, 26, 28 2. Inc. c., con jerarquía constitucional Ley 27.044); Convención Interamericana para la Eliminación de todas las formas de Discriminación Contra las Personas con Discapacidad (art. 2, 3, 4 y 7, receptada en nuestro derecho interno por ley 25.280); Convención Interamericana Para Prevenir, Sancionar y Erradicar la Violencia Contra la Mujer "Convención Belem Do Pará" (art. 3, 4, 5, 6, 7)] 
cia necesarias para que las familias puedan contribuir a que las personas con discapacidad gocen de sus derechos plenamente y en igualdad de condiciones...". A su vez, posiciona al Estado como un actor fundamental para garantizar el derecho a recibir protección y cuidados, también reconocido por el Comité de los Derechos del Niño en la Observación General No 9, en la que se sostuvo que "las causas, la prevención y el cuidado de las discapacidades no recibe la tan necesaria atención en los programas de investigación nacionales e internacionales, y se alienta a los Estados Partes a que asignen prioridad a esta cuestión y garanticen la financiación y la supervisión de la investigación centrada en la discapacidad, prestando especial atención a su aspectico ético."10

\section{NORMAS QUE REGULAN EL CUIDADO}

Al consultar fuentes estadísticas para evaluar la eficacia de los planteos sobre cuidados, se observa un incremento exponencial de los procesos de amparo en los que se reclaman prestaciones de salud, que alcanzan cerca del 45,60 \% del total de los expedientes iniciados en los Tribunales Federales Civiles y Comerciales de la CABA ${ }^{11}$. Esto implica la, aceleración de los tiempos para producir respuestas jurisdiccionales dado los breves plazos previstos para tramitarlos (48 hs.), lo que indica que se traduce en una mayor presión para la toma de decisiones urgentes, que impactará en la intensidad y volumen de trabajo de cada uno de los organismos de la justicia intervinientes, encontrando estas demandas nuevas barreras generadas en el propio ámbito jurisdiccional.

El escenario descripto demuestra que la administración de justicia no ha es indiferente a los cambios sociales vinculados con el empobrecimiento de la población, la incorporación masiva de las mujeres al empleo, el envejecimiento del envejecimiento de la población y su feminización, a la mayor prevalencia a adquirir enfermedades crónicas, al incremento de los requerimientos de cuidado de las personas -tengan o no una discapacidad que les genere dependencia-, inclusive las situaciones de alta dependencia -no olvidemos que el $15 \%$ de nuestra población presenta algún tipo de discapacidad y el 13\% de ellas tiene tres o más dificultades-. Muy por el contrario, el Poder Judicial, se ha constituido en un actor estratégico para evitar que se produzca la violación de derechos humanos fundamentales.

PERO, ¿QUÉ SUCEDE CUANDO SE PLANTEAN RECLAMOS POR CUIDADO ANTE LA JUSTICIA?

Frente a la obligación de garantizar el acceso a la justicia y los derechos fundamentales afectados, la Magistratura argentina ehibe larga experiencia en pronunciamientos sobre el cuidado médico-asistencial ${ }^{12}$, el cuidado personal, al fijar el monto de una compensación económica, al cuantificar el valor de la vida o la incapacidad producida en el ámbito laboral,

10 Observación General No 9. Comité CDN. Punto 61.Pagina

11 Estadísticas de amparos/ sumarísimos de salud año 2015 al 2019 . Cifra obtenida del total de los ingresos en el fuero civil y comercial federal. (*) Fecha de corte 10.9.2019.

12 Caso Lifschitz (2004) es uno de los casos más importantes que en toda sentencia en materia de requerimientos del cuidado de la salud de PCD. Otros reclamos están vinculados con la Asistencia Domiciliaria prevista en el art. 39 inc. d) de la Ley 24.901 o el Acompañamiento Terapéutico del art. 12 de la ley 26.657. 
incluso al conceder una excarcelación o prisión domiciliaria ${ }^{13}$, etc., que han obtenido reconocimiento jurídico favorable sustentado en normas de jerarquía constitucional que resguardaban la protección del derecho a la vida, la salud, y la integridad física, entre otros.

Este posicionamiento jurisprudencial frente a las demandas de cuidados basados en el Pacto Internacional de Derechos Económicos, Sociales y Culturales, la Convención de los Derechos del Niño, la Convención Sobre los Derechos de las Personas con Discapacidad ${ }^{14}$, la Convención Interamericana Sobre la Protección de los Derechos Humanos de las Personas Mayores ${ }^{15}$, el art. 75 inc. 22 y 23 de la Constitución Nacional, el Código Civil y Comercial de la Nación, la ley $24.901^{16}$ y la Ley de Salud Mental № 26.657 (art. 12), entre otras tantas leyes específicas, importa visibilizar la trascendencia que tiene el cuidado en la vida de las personas, garantizándose judicialmente un entorno que le proporcione sostenibilidad, resignificándose situaciones que el derecho siempre abordó, e incluyendo los aspectos más básicos de la vida cotidiana donde la judicatura no puede quedar ausente.

La justicia ha ido construyendo desde hace mucho tiempo la noción de protección especial como estrategia para cubrir las particulares circunstancias que atraviesan las personas en situación de dependencia, las institucionalizas, o riesgo (niñas, niños y adolescentes, personas mayores o con discapacidad, mujeres, personas LGTTTBYQ, etc.). En la jurisprudencia de la Corte Suprema de Justicia de la Nación hay pronunciamientos históricos que marcan un posicionamiento político institucional frente a determinadas problemáticas. A los efectos de este trabajo me detendré en el análisis del caso Lifschitz del año 2004, que brinda lineamientos precisos sobre el posicionamiento del poder judicial en estos casos, expone la función y limitaciones de la judicatura, y es uno de los más presentes en la jurisprudencia de la Justicia Civil y Comercial Federal sobre salud.

En él, la Corte toma los argumentos del Procurador General de la Nación, sostuvo que las personas con discapacidad "además de la especial atención que merecen de quienes están directamente obligados a su cuidado, requiere también la de los jueces y de la sociedad toda, siendo su interés la consideración primordial, lo viene a tanto a orientar como a condicionar la decisión de los jueces llamados a juzgamiento en todos los casos" (doctrina de fallos: $322: 2701 ; 324: 122)^{17}$.

Como nota destacada se observa que en esta respuesta jurisdiccional se identificó a todos los actores y responsables de garantizar el cuidado, no solo las familias, sino también los agentes de salud, la sociedad, y la judicatura, deben cumplir con la obligación señalada expresamente por el Máximo Tribunal y están condicionados frente a la necesidad de las PCD que necesitan cuidados. Un nuevo comportamiento se impuso, aquél que advertía la necesidad de modificar los patrones tradicionales que desconocían las desigualdades de este colectivo, para transformarse en protagonistas de la especial protección.

13 Art. 10 CPPN y el art. 32 de la Ley de ejecución pena privativa de libertad Nro. 23.660 (mod. Por Ley Nro. 26.472).

14 La Convención se concibió como un instrumento para garantizar los derechos humanos de las personas con discapacidad con una dimensión explicita de desarrollo social.

15 Art. 3 inc. f) y art. 12 y19.

16 Ley 24.901. Art. 39 inc. d. (mod. por ley 26.480).

17 CSJN. Caso Lifscitz, Graciela Beatriz y otros c/ Estado Nacional. 15 de junio de 2004. 


\section{DEMANDAS JUDICIALES DE CUIDADO}

Al consultar fuentes estadísticas para evaluar la eficacia de los planteos sobre cuidados, se observa un incremento exponencial de los procesos de amparo en los que se reclaman prestaciones de salud, que alcanzan cerca del $45,60 \%$ del total de los expedientes iniciados en los Tribunales Federales Civiles y Comerciales de la CABA ${ }^{18}$. Esto implica la, aceleración de los tiempos para producir respuestas jurisdiccionales dado los breves plazos previstos para tramitarlos (48 hs.), lo que indica que se traduce en una mayor presión para la toma de decisiones urgentes, que impactará en la intensidad y volumen de trabajo de cada uno de los organismos de la justicia intervinientes, encontrando estas demandas nuevas barreras generadas en el propio ámbito jurisdiccional.

El escenario descripto demuestra que la administración de justicia no ha es indiferente a los cambios sociales vinculados con el empobrecimiento de la población, la incorporación masiva de las mujeres al empleo, el envejecimiento del envejecimiento de la población y su feminización, a la mayor prevalencia a adquirir enfermedades crónicas, al incremento de los requerimientos de cuidado de las personas -tengan o no una discapacidad que les genere dependencia-, inclusive las situaciones de alta dependencia -no olvidemos que el $15 \%$ de nuestra población presenta algún tipo de discapacidad y el 13\% de ellas tiene tres o más dificultades-. Muy por el contrario, el Poder Judicial, se ha constituido en un actor estratégico para evitar que se produzca la violación de derechos humanos fundamentales.

PERO, ¿QUÉ SUCEDE CUANDO SE PLANTEAN RECLAMOS POR CUIDADO ANTE LA JUSTICIA?

Frente a la obligación de garantizar el acceso a la justicia y los derechos fundamentales afectados, la Magistratura argentina exhibe larga experiencia en pronunciamientos sobre el cuidado médico-asistencial ${ }^{19}$, el cuidado personal, al fijar el monto de una compensación económica, al cuantificar el valor de la vida o la incapacidad producida en el ámbito laboral, incluso al conceder una excarcelación o prisión domiciliaria ${ }^{20}$, etc., que han obtenido reconocimiento jurídico favorable sustentado en normas de jerarquía constitucional que resguardaban la protección del derecho a la vida, la salud, y la integridad física, entre otros.

Este posicionamiento jurisprudencial frente a las demandas de cuidados basados en el Pacto Internacional de Derechos Económicos, Sociales y Culturales, la Convención de los Derechos del Niño, la Convención Sobre los Derechos de las Personas con Discapacidad ${ }^{21}$, la Convención Interamericana Sobre la Protección de los Derechos Humanos de las Personas Mayores $^{22}$, el art. 75 inc. 22 y 23 de la Constitución Nacional, el Código Civil y Comercial de la Nación, la ley $24.901^{23}$ y la Ley de Salud Mental № 26.657 (art. 12), entre otras tantas leyes

18 Estadísticas de amparos/ sumarísimos de salud año 2015 al 2019 . Cifra obtenida del total de los ingresos en el fuero civil y comercial federal. (*) Fecha de corte 10.9.2019.

19 Caso Lifschitz (2004) es uno de los casos más importantes que en toda sentencia en materia de requerimientos del cuidado de la salud de PCD. Otros reclamos están vinculados con la Asistencia Domiciliaria prevista en el art. 39 inc. d) de la Ley 24.901 o el Acompañamiento Terapéutico del art. 12 de la ley 26.657.

20 Art. 10 CPPN y el art. 32 de la Ley de ejecución pena privativa de libertad Nro. 23.660 (mod. Por Ley Nro. 26.472).

21 La Convención se concibió como un instrumento para garantizar los derechos humanos de las personas con discapacidad con una dimensión explicita de desarrollo social. 
específicas, importa visibilizar la trascendencia que tiene el cuidado en la vida de las personas, garantizándose judicialmente un entorno que le proporcione sostenibilidad, resignificándose situaciones que el derecho siempre abordó, e incluyendo los aspectos más básicos de la vida cotidiana donde la judicatura no puede quedar ausente.

La justicia ha ido construyendo desde hace mucho tiempo la noción de protección especial como estrategia para cubrir las particulares circunstancias que atraviesan las personas en situación de dependencia, las institucionalizas, o riesgo (niñas, niños y adolescentes, personas mayores o con discapacidad, mujeres, personas LGTTTBYQ, etc.). En la jurisprudencia de la Corte Suprema de Justicia de la Nación hay pronunciamientos históricos que marcan un posicionamiento político institucional frente a determinadas problemáticas. A los efectos de este trabajo me detendré en el análisis del caso Lifschitz del año 2004, que brinda lineamientos precisos sobre el posicionamiento del poder judicial en estos casos, expone la función y limitaciones de la judicatura, y es uno de los más presentes en la jurisprudencia de la Justicia Civil y Comercial Federal sobre salud.

En él, la Corte toma los argumentos del Procurador General de la Nación, sostuvo que las personas con discapacidad "además de la especial atención que merecen de quienes están directamente obligados a su cuidado, requiere también la de los jueces y de la sociedad toda, siendo su interés la consideración primordial, lo viene a tanto a orientar como a condicionar la decisión de los jueces llamados a juzgamiento en todos los casos" (doctrina de fallos: $322: 2701 ; 324: 122)^{24}$.

Como nota destacada se observa que en esta respuesta jurisdiccional se identificó a todos los actores y responsables de garantizar el cuidado, no solo las familias, sino también los agentes de salud, la sociedad, y la judicatura, deben cumplir con la obligación señalada expresamente por el Máximo Tribunal y están condicionados frente a la necesidad de las PCD que necesitan cuidados. Un nuevo comportamiento se impuso, aquél que advertía la necesidad de modificar los patrones tradicionales que desconocían las desigualdades de este colectivo, para transformarse en protagonistas de la especial protección.

\section{DESAFÍOS PARA GARANTIZAR EL CUIDADO}

Una nota significativa e insoslayable en relación con el trabajo de cuidado, es que se instituye como una práctica atravesada por sentimientos de amor, solidaridad, lealtad; por normas sociales, éticas, morales y por mandatos culturales y de género, que llevan a naturalizar, legitimizar y reproducir el protagonismo de las mujeres en esas tareas, incluso cuando ello tenga efectos adversos para la propia salud ${ }^{25}$. Debido a que en nuestra cultura aún persiste en la familia una inequitativa distribución de las responsabilidades de cuidado, es obligación del Estado aplicar en estos casos la Convención Sobre la Eliminación de Todas las Formas 
de Discriminación contra la Mujer y la Convención Belem do Pará ${ }^{26}$, para examinar leyes ${ }^{27}$ y políticas neutrales en cuanto al género y asegurarse de que no crean o perpetúan las desigualdades existentes ${ }^{28}$.

Es decir, si bien el cuidado -como mecanismo comportamental implementado históricamente para la sostenibilidad de la vida de las personas- ha sido reconocido desde hace décadas por nuestros Tribunales, aún requiere en el proceso de decisión, se valore e incorpore, el mayor impacto que provoca en las vidas de quienes proveen cuidados en la familia, principalmente de las mujeres, y aplicar las normas y estándares internacionales establecidos en su protección.

En definitiva, esta valoración jurisdiccional deberá profundizar en la observancia del emplazamiento en el que se produce la relación de cuidado (institucionalizado o doméstico), en las personas que intervienen (familia, mujeres, agentes de salud obligados a brindar apoyos), y cuando ellos sean solicitados en instancias administrativas o jurisdiccionales, atender a la responsabilidad de los actores que intervienen, el tiempo que requiere su provisión, la distribución en función de la intensidad en relación del tipo de discapacidad y/o nivel de dependencia, y las prestaciones contempladas en nuestro ordenamiento jurídico para apoyar a las familias en el proceso de integración y cuidado de las PCD.

A nivel infraconstitucional y local, se desarrolló un corpus jurídico a través de un extenso aunque asistemático conjunto normativo con eje en distintos aspectos: el reconocimiento de apoyos ${ }^{29}$, la incorporación de la perspectiva de género ${ }^{30}$, su transversalidad y la eliminación de estereotipos de género ${ }^{31}$; el procesamiento de datos con perspectiva de género ${ }^{32}$; el impulso y medición de la igualdad de responsabilidades en el hogar entre el hombre y la mujer ${ }^{33}$; la prohibición de discriminación, entre otras.

Estas observaciones, permiten plantear desde una perspectiva de derechos la importancia de producir respuestas jurisdiccionales en materia de cuidado ${ }^{34}$ (terapéutico/asistencial)

26 Convención Interamericana para Prevenir, Sancionar y Erradicar la Violencia Contra la Mujer (art. 3, 4, 6 inc. a y 7 inc. e).

27 Ley de protección integral a las mujeres Nro. 26.485 (mod. por Ley 27.501 y 27.533).

28 Recomendación general núm. 28, párr. 16.

29 Art. 39 inc. d) de la Ley 24.901 que prevé la figura de asistencia domiciliaria, y art. 12 de la Ley 26.657 que reconoce la necesidad de acompañamiento terapéutico como dispositivo ante situaciones donde el tratamiento de salud mental aconseja su externación y permanencia en domicilio.

30 Ley de capacitación obligatoria en la temática de género y violencia contra las mujeres Nro. 27.499.; Ley 26.485 de protección integral a las mujeres Art. 7 inc. d).

31 En relación con los estereotipos de género, en el Caso Artavia Murillo y otros (Fecundación in vitro) Vs. Costa Rica. Excepciones Preliminares, Fondo, Reparaciones y Costas. Sentencia de 28 de noviembre de 2012, la Corte Interamericana resalta que estos estereotipos de género son incompatibles con el derecho internacional de los derechos humanos y se deben tomar medidas para erradicarlos. El Tribunal no está validando dichos estereotipos y tan sólo los reconoce y visibiliza para precisar el impacto desproporcionado de la interferencia generada por la sentencia de la Sala Constitucional (Parágrafo 302) y en el Caso Espinoza González vs. Perú. Excepciones Preliminares, Fondo, Reparaciones y Costas. Sentencia 20 de noviembre de 2014. Al respecto, consideró que el estereotipo de género se refiere a una pre-concepción de atributos o características poseídas o papeles que son o deberían ser ejecutados por hombre y mujeres respectivamente. La Corte ha identificado estereotipos de género que son incompatibles con el derecho internacional de los derechos humanos y respecto de los cuales los Estados deben tomar medidas para erradicarlos. Parágrafo 268.

32 La Ley CABA $n^{\circ} 5588$ de inclusión del área temática de Derechos Humanos para la producción de indicadores y publicación de estadísticas y la Ley CABA $n^{\circ} 5924$, BOCBA N 5290 del 09/01/2018, garantiza la incorporación del enfoque de género en todas las producciones del Sistema Estadístico de la Ciudad Autónoma de Buenos Aires. La Ley CABA n 4.181 establece el servicio de atención telefónica gratuita LINEA MUJER.

33 Ley CABA n 4892, BOCBA N 4333 del 05/02/2014, para impulsar acciones sobre la contribución de la economía del cuidado. 34 Ley CABA $n^{\circ} 5261$, Ley contra la discriminación. 
que disminuyan el familismo ${ }^{35}$, las asimetrías sociales y de género, distribuyendo equitativamente las responsabilidades entre los diferentes actores involucrados en el cuidado de las PCD, garantizando a las familias y a su interior a la principal proveedora, tiempo de descanso, acceso a la educación, el cuidado de otros miembros dependientes, tiempo para establecer y mantener redes conversacionales que le brinden contención emocional, y el acceso a la información para poder solicitar los apoyos necesarios para garantizar la sostenibilidad del dispositivo de cuidado que la familia y los profesionales tratantes de la PCD requieran.

\section{BIBLIOGRAFÍA}

BROVELLI, Karina. Cuando el cuidado no es un asunto de mujeres. Organización de los cuidados por parte de personas en situación de vulnerabilidad psico/social. Revista Argentina de Terapia Ocupacional. Año 1. Nro. 1. Diciembre de 2015. ISSN. 2469-1143.

FINDLING, Liliana. Mario Silvia y Champalbert Laura. Como cuidan y se cuidan las mujeres del Gran Buenos Aires. Población de Buenos Aires. Vol. 11. Num. 20 de octubre. 2014, pp. 40).

PONCE, Marisa. "El cuidado de la salud de los que cuidan", en de cuidados y cuidado de las acciones públicas y privadas. Ed. Biblos, Ciudad de Buenos Aires. 2015. Pág. 156.

POPE-NOE, 1988;1994 citado por Adela Garzón "Familismo y creencias políticas" en Revista de Psicología Política, Nro. 17, 1998, 101-128). Consultado el 18/3/2020. Disponible en: https://www.us.es/garzon/psicología\%20 politica/N17-5.pdf.

RAMACIOTTI, Karina; ZANGARO, Marcela. "Los derroteros del cuidado". Universidad de Quilmes. ISBN 978-987558-550-8. 1ra. Edición. Provincia de Buenos Aires. 2019:9.

SÁNCHEZ VERA, Pedro; DÍAZ, Marcos Bote. "Familismo y cambio social. El caso de España Sociologías". Revista Dossiê. Porto Alegre, Nro. 21. 2009:122. Consultado el 18/3/2020. Disponible en: http://www.scielo.br/pdf/soc/ n21/07.pdf.

\section{Referencias Normativas}

Constitución Nacional

Código Civil y Comercial de la Nación

Declaración Americana de los Derechos y Deberes del Hombre

Declaración Universal de Derechos Humanos

Convención sobre los Derechos del Niño (CDN)

Convención Sobre La Eliminación de Todas Las Formas De Discriminación contra la Mujer (CEDAW)

35 El concepto de familismo remite al modelo de los países mediterráneos en el cual se observa una confianza permanente en la familia para la provisión de trabajo y servicios asistenciales, tanto en su solidaridad intergeneracional como en su estructura de género (Cfr. Findling, Liliana, Mario Silvia y Champalbert Laura. "Como cuidan y se cuidan las mujeres del Gran Buenos Aires. Población de Buenos Aires. Vol. 11. Num. 20 de octubre. 2014, pp. 40). Según otras investigaciones el familismo, en un sentido genérico, se refiere a la creencia cada vez más extendida en la importancia de la familia y, por tanto, la necesidad de desarrollar programas de apoyo y defensa de la institución familiar (Pope-noe, 1988;1994 citado por Adela Garzón "Familismo y creencias políticas" en Revista de Psicología Política, Nro. 17, 1998, 101-128). Consultado el 18/3/2020. Disponible en: https://www.us.es/garzon/psicología\%20politica/N17-5.pdf. Otros autores señalan que "el familismo de las sociedades está frecuentemente ligado a las limitaciones que presentan los Estados de Bienestar al hacer recaer sobre ellas un protagonismo excesivo.". Sánchez Vera, Pedro y Marcos Bote Díaz. "Familismo y cambio social. El caso de España Sociologías". Revista Dossiê. Porto Alegre, Nro. 21. 2009:122. Consultado el 18/3/2020. Disponible en: http://www.scielo.br/pdf/soc/ n21/07.pdf. 
Convención Interamericana para Prevenir, Sancionar y Erradicar la Violencia contra La Mujer "Convención de Belem do Pará"

Mecanismo de Seguimiento de la Convención Belém do Pará (MESECVI)

Convención sobre los Derechos de las Personas con Discapacidad

Convención Americana Sobre Derechos Humanos (CADH)

Declaración Universal de Derechos Humanos (DUDH)

Pacto Internacional de Derechos Económicos, Sociales y Culturales (PIDESC)

personas con Discapacidad.

Convención Interamericana Sobre la Protección de los Derechos Humanos de las Personas Mayores

Ley 24.901 y sus modificaciones (Ley $N^{\circ} 26.480$ )

Ley de Salud Mental N² 26.657. Decreto 603/13

Ley 26.485. Protección Integral de las Mujeres

Ley Nro. 27.499 de capacitación obligatoria en la temática de género y violencia contra las mujeres.

Observación General Nro. 28 de la CEDAW

Observación General № 9. Comité CDN.

La Ley CABA n 5588 de inclusión del área temática de Derechos Humanos para la producción de indicadores y publicación de estadísticas

Ley CABA n 5924, BOCBA N 5290 del 09/01/2018, garantiza la incorporación del enfoque de género en todas las producciones del Sistema Estadístico de la Ciudad Autónoma de Buenos Aires.

Ley CABA n 4.181 establece el servicio de atención telefónica gratuita LINEA MUJER.

INFORME REGIONAL SOBRE LA MEDICIÓN DE LA DISCAPACIDAD Una mirada a los procedimientos de medición de la discapacidad en América Latina y el Caribe.

Ley CABA n 5261, Ley contra la discriminación.

Ley CABA n 4892, BOCBA N 4333 del 05/02/2014, para impulsar acciones sobre la contribución de la economía del cuidado.

Recebido/Received: 17.05.2020

Aprovado/Approved: 20.05.2020 